\title{
PELESTARIAN KAWASAN TANJUNG PURA SEBAGAI ASET WISATA DI KABUPATEN LANGKAT
}

\author{
Meyga Fitri Handayani Nasution1, Dharma Widya² \\ ${ }^{1}$ Fakultas Teknik Sipil dan Perencanaan, Institut Teknologi Medan \\ email: imychey@yahoo.com \\ ${ }^{2}$ Fakultas Teknik Sipil dan Perencanaan, Institut Teknologi Medan \\ email: widya65@gmail.com
}

\begin{abstract}
ABSTRAK
Dahulu Tanjung Pura ibukota Kesultanan Melayu Langkat yang menyimpan berbagai benda cagar budaya dari peninggalan Kesultanan Melayu dan masa kolonial Belanda. Keanekaragaman benda cagar budaya di Tanjung Pura seperti kawasan dan bangunan-banguan bersejarah ini sangat berpotensi sebagai aset wisata di Kota Tanjung Pura. Untuk itu perlu usaha pelestarian sehingga Kota Tanjung Pura tidak hanya menjadi sejarah saja nantinya. Target khusus dari penelitian ini adalah pelestarian kawasan di Tanjung Pura agar dapat menjadi aset wisata arsitektur dan budaya. Hasil dari penelitian berupa konsep rancangan, konsep pelestarian, desain rancangan kawasan dan dokumentasi berupa foto dan gambar bangunan bersejarah dengan menggunakan program desain. Metode yang digunakan adalah observasi langsung, membuat zona-zona kawasan dan mengambil sampel beberapa bangunan bersejarah di setiap zona, pengukuran, membuat sketsa dan dokumentasi untuk sampel bangunanbangunan bersejarah. Hasil pengukuran dan sketsa di lapangan digambarkan menggunakan program desain, membuat analisis dan konsep perancangan untuk kawasan yang ingin dijadikan objek wisata.
\end{abstract}

Kata kunci: Kota Tanjung Pura, pelestarian, wisata arsitektur

\begin{abstract}
Tanjung Pura, formerly was the capital of Malay Sultanate of Langkat, had various cultural heritage of Malay Sultanate and Dutch colonial. Diversity of those objects (historic buildings and other relics) is potential for tourism. It needs conservation efforts. Specific target of this research is to preserve some area in Tanjung Pura to become asset of architectural and cultural tourism. Results of this research is design concept, preservation concept, regional planning and documentation (historic buildings photoes and pictures) by design program. The methods used in this study are direct observation, determining zones to take samples of historic buildings, measuring, making sketches and documents for every sample. The results of field measuring and sketching were represented using design program, to be analyzed and synthesized to propose design concept for certain area planned as tourist destination.
\end{abstract}

Keywords: City Of Tanjung Pura, preservation, tourism architecture 


\section{Pendahuluan}

\subsection{Latar Belakang}

Isu tentang pelestarian kawasan bersejarah terutama kota-kota tua saat ini sudah banyak dilakukan oleh beberapa negara di dunia, seperti negara Jepang, Belanda, Singapore, dan negara-negara lainnya. Contohnya negara Singapore yang awalnya mengganti bangunan-bangunan dan kawasan bersejarah dengan wujud baru dengan masuknya modernisasi, tetapi kurangnya minat wisatawan datang ke Singapore membuat pemerintah sadar untuk mengembalikan wajah kota bersejarah tersebut sehingga muncullah beberapa kawasan seperti Kampung Melayu, Little India, dan China Town di Singapore. Sehingga saat ini objek wisata di Singapore berupa bangunan kuno, pasca modern dan modern.

Di Indonesia sendiri beberapa kota sudah menerapkan pelestarian kawasan-kawasan bersejarah maupun bangunan-bangunan bersejarah yang dianggap sebagai cagar budaya arsitektur, seperti di kota Jakarta, Semarang, Bandung, Surabaya, dan saat ini di ikuti beberapa kota lainnya di Indonesia, seperti Samarinda, Donggala, Surakarta dan kota lainnya, bahkan sampai ke kota-kota kecil yang ada di Indonesia. Kawasan dan bangunan-bangunan bersejarah yang ada di Indonesia bukan saja bangunan-bangunan yang ditinggalkan oleh Belanda, tetapi ada pula yang merupakan peninggalan-peninggalan dari kerajaan-kerajaan yang pernah ada di Indonesia, termasuk didalamnya adalah rumah adat. Jadi cagar budaya arsitektur di Indonesia sangat beragam, dari peninggalan kolonial Belanda, peninggalan kerajaan berupa candi-candi, istana, tempat ibadah, bangunan tradisional seperti rumah adat tiap daerah di Indonesia, dan terdapat pula bangunan-bangunan yang bercirikan etnis tertentu seperti China, Arab dan India. Kawasan dan bangunan bersejarah di Indonesia tidak saja ditemui di kota-kota besar tetapi banyak juga ditemui di kota-kota kecil seperti kabupaten dan kecamatan, salah satunya adalah Kota Tanjung Pura.

Kota Tanjung Pura dahulunya merupakan ibukota Kesultanan Melayu Langkat. Sebagai ibukota Kesultanan Melayu Langkat, Tanjung Pura tentunya dulu memiliki sarana prasarana pemerintahannya sendiri, seperti istana, balai pertemuan, balai peradilan, penjara, rumah raja, masjid, sekolah, dan lain-lain. Selain itu masuknya beberapa etnis di Tanjung Pura seperti Arab dan India yang bertujuan untuk berdagang dan menyebarkan agama Islam, muncul bangunan ibadah, lalu masuknya etnis China sehingga muncul pertokoan dan tempat ibadah, dan masuk juga Belanda ke Kota Tanjung Pura sehingga muncul rumah-rumah Belanda dan kantor-kantor pemerintahan dan fasilitas umum seperti rumah sakit dan kantor pos. Saat ini kawasan dan bangunan-bangunan bersejarah di Tanjung Pura sebagian masih difungsikan seperti awalnya, tetapi sebagian telah beralih fungsi, bahkan sebagian bangunan-bangunan tersebut banyak yang rusak tidak terawat bahkan hilang. Semua kawasan dan bangunan-bangunan di masa Kesultanan Melayu dan Kolonial Belanda merupakan peninggalan bersejarah yang terdapat Tanjung Pura dan layak untuk dilestarikan.

Seperti yang telah dijelaskan di atas bahwa pertumbuhan Kota Tanjung Pura selain dipengaruhi oleh Belanda juga banyak dipengaruhi oleh beberapa etnis pendatang, seperti China (Tionghoa), Arab, dan India. Hal ini dapat dilihat dari 
arsitektur yang terdapat di Kota Tanjung Pura, tidak hanya bercirikan Melayu tetapi banyak juga bangunan dengan ciri arsitektur China, Arab dan India, termasuk juga bercirikan kolonial Belanda, dalam berarsitektur Belanda sangat memperhatikan budaya dan kondisi setempat, jadi wujud bangunan yang ada selalu memasukan ciri budaya lokal, seperti penggunaan atap tajuk dan ornamen Melayu pada bangunannya. Jadi jika dilihat dari ciri-ciri bangunan dibeberapa kawasan Tanjung Pura diperkirakan bahwa adanya pembagian wilayah dari kota berdasarkan etnis tersebut, seperti adanya kawasan Melayu, kawasan China, dan kawasan kolonial Belanda. Keberagaman budaya yang terdapat di Kota Tanjung Pura menjadikan kota ini sebagai kota budaya. Selain itu Tanjung Pura juga dijuluki dengan kota pendidikan, hal ini dikarenakan beberapa tokoh nasional seperti Tengku Amir Hamzah dan Adam Malik pernah menimba ilmu di bumi Melayu Langkat ini. Dan sampai saat ini pendidikan-pendidikan bernuansa Islam masih tumbuh berkembang di Tanjung Pura.

Kondisi saat ini bangunan-bangunan peninggalan Kesultanan Melayu Langkat perlahan-lahan mulai hilang. Satu per satu bangunan rusak dan dirobohkan untuk menghadirkan bangunan baru yang lebih modern. Kondisi ini sangat memprihatikan mengingat kota ini memiliki cagar budaya yang sangat berpotensi bila dikembangkan akan menjadi aset daerah.

Untuk itu perlu adanya perhatian khusus untuk cagar budaya yang terdapat di Tanjung Pura ini seperti melakukan pelestarian kawasan dan bangunanbangunan guna untuk melindungi, merawat, mempertahankan dengan cara membuat konsep penataan dan perawatan yang baik sehingga nantinya Tanjung Pura dapat menjadi daya tarik wisatawan lokal maupun manca negara untuk datang ke kota ini.

Selain itu perlu melakukan pendataan dan pendokumentasian dari tiap-tiap bangunan bersejarah yang masih ada gunanya untuk refrensi bagi para wisatawan dan juga untuk pendidikan sejarah bagi generasi penerus bangsa agar tidak melupakan sejarah bangsanya. Selain itu diharapkan hasil penelitian ini nantinya dapat digunakan oleh pemerintah setempat sebagai acuan dalam melakukan pelestarian dan perawatan kawasan dan bangunan cagar budaya yang ada di Tanjung Pura.

\subsection{Rumusan Permasalahan}

Pelestarian merupakan suatu upaya perlindungan, pengembangan dan pemanfaatan bangunan atau lingkungan konservasi yang mendayagunakan bendabenda cagar budaya untuk kepentingan agama, sosial, ekonomi, pariwisata, pendidikan, ilmu pengetahuan, dan kebudayaan. Wilayah yang ditetapkan sebagai benda cagar budaya mutlak ditetapkan untuk kepentingan perlindungan dan pemanfaatan, yang terdiri dari mintakatkan inti, penyangga dan pengembangan. Jika berbicara tentang pelestarian suatu kawasan dan bangunan tidak terlepas dari pengguna bangunan yang dilestarikan dan juga pemerintah daerah. Sehingga ada beberapa permasalahan yang akan dihadapi dalam pelestarian ini, yaitu:

a. Bagaimana memberi masukan kepada pemerintah daerah setempat tentang pentingnya dilakukan pelestarian kawasan dan bangunan-bangunan bersejarah di Tanjung Pura sebagai cagar budaya yang mampu mendatangkan 
income dengan memberikan konsep pelestarian berupa desain rancangan pelestarian.

b. Bagaimana merancang satu kawasan wisata arsitektur dan budaya di jalan utama Tanjung Pura yang merupakan jalan lintas Sumatera, perlu perencanaan sirkulasi alternatif kendaraan untuk lintas Sumatera.

\section{Metode Penelitian}

\subsection{Lokasi Pengambilan Data dan Alat yang digunakan}

Penelitian dilakukan di Tanjung Pura Kabupaten Langkat. Dilakukan pengukuran pada kawasan dengan menggunakan alat GPS lalu digambarkan dengan menggunakan software desain yaitu Autocad dan Ilustrator.

Tiap zona kawasan memiliki bangunan-bangunan bersejarah, maka diambil beberapa bangunan untuk mewakili tiap kawasan. Dilakukan pengukuran pada tiap bangunan dengan menggunakan meteran, lalu membuat sketsa tiap bangunan dengan menggunakan kertas milimeter, dan digambarkan dengan menggunakan software desain Autocad dan Ilustrator. Selain itu dilakukan pendokumentasian setiap bangunan dengan menggunakan kamera digital.

\subsection{Teknik Pengumpulan Data}

Pengumpulan data yang dilakukan pada penelitian ini yaitu survei data primer dan survei data skunder. Untuk data primer didapat dengan cara observasi langsung di lapangan, dilakukan pengukuran, pembuatan sketsa, pendokumentasian dengan kamera digital dan video. Sedangkan untuk data sekunder didapatkan dengan cara studi literatur dari perpustakaan daerah di Medan, perpustakaan Melayu, Museum Tanjung Pura, dan wawancara dengan ahli sejarah di Tanjung Pura.

Untuk pengambilan sampel bangunan bersejarah di setiap kawasan dilakukan dengan melihat kriteria konservasi yaitu, usia bangunan, estetika, landmark sebuah kawasan, dan gaya arsitektural.

\subsection{Prosedur Penelitian}

Tahapan pelaksanaan penelitian ini adalah sebagai berikut:

a. Tahap survei data skunder yaitu mengumpulkan data literatur yang di dapat dari perpustakaan daerah di Medan, perpustakaan Melayu di Medan, Museum Tanjung Pura dan wawancara dengan ahli sejarah dari Tanjung Pura.

b. Tahap survei data primer, observasi langsung di lapangan yaitu Tanjung Pura:

- melakukan pemetaan bangunan-bangunan bersejarah

- membagi zona kawasan berdasarkan ciri bangunan yang terdapat di tiap zonanya

- pendataan tiap-tiap bangunan bersejarah di setiap zona kawasan, dilakukan pengukuran, pembuatan sketsa dan pendokumentasian dengan kamera digital untuk mengambil detail-detail arsitektur sehingga memudahkan dalam penggambaran 
c. Tahap penggambaran yaitu data primer yang didapatkan di lapangan digambarkan dengan menggunakan software desain Autocad dan Ilustrator.

d. Tahap pembuatan konsep yaitu membuat konsep rancangan untuk kawasan perkotaan (zona Melayu dan zona Pecinan) yang akan dijadikan objek wisata sejarah, konsep rancangan dituangkan dalam gambar desain, seperti desain pedestrian, desain parkir, desain sirkulasi, dan lain-lain.

\section{Hasil Dan Pembahasan}

\subsection{Pembagian Kawasan di Kota Tanjung Pura}

Dari hasil survei dan pengamatan langsung di lapangan dengan melihat arsitektur (bangunan-bangunan) yang ada maka Kota Tanjung Pura dapat dibagi menjadi 3 kawasan. Dan dari 3 kawasan tersebut, diambil masing-masing 1 (satu) bangunan yang bisa dijadikan vocal point mewakili tiap kawasan yaitu:

a. Mesjid Azizi untuk kawasan Melayu

b. Klenteng untuk kawasan Pecinan

c. Kantor Pos untuk kawasan Belanda

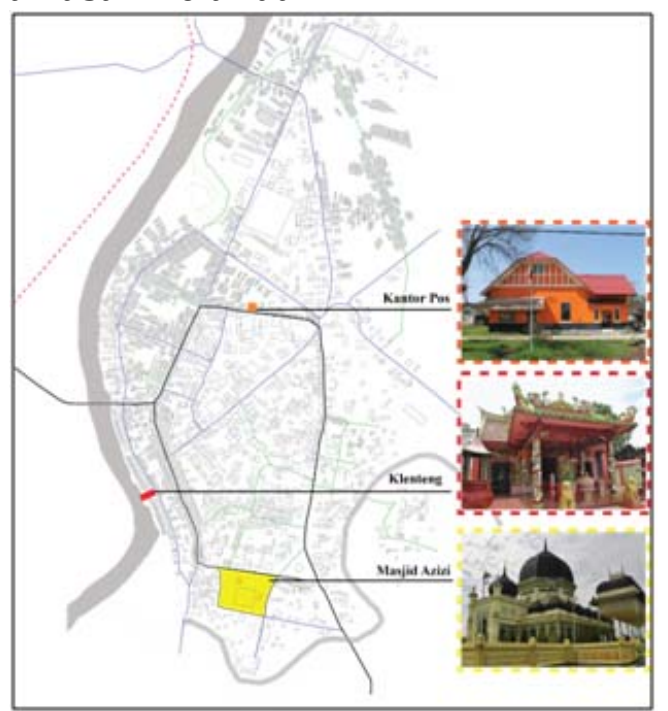

Gambar 1. Bangunan yang Mewakili Tiap Kawasan

Maka untuk pembagian kawasan dapat dilihat pada peta dibawah ini.

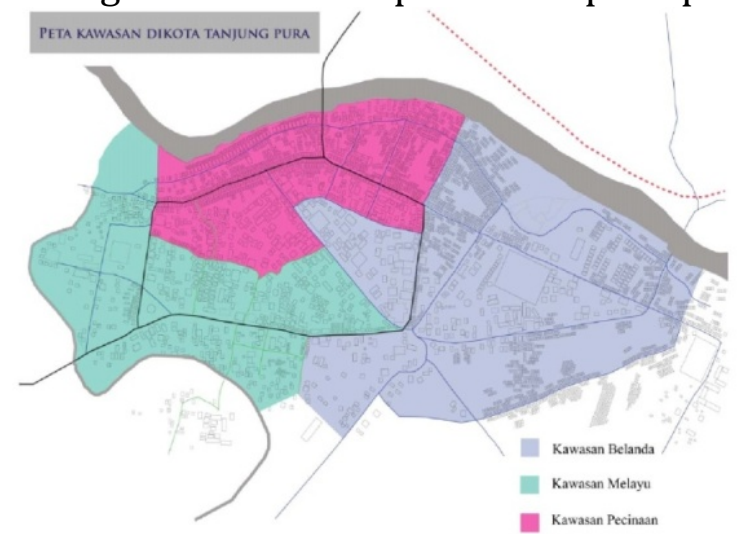

Gambar 2. Pembagian Kawasan Berdasarkan Arsitektur yang Dominan 


\subsubsection{Pemetaan dan Pendataan Bangunan di Kawasan Melayu}

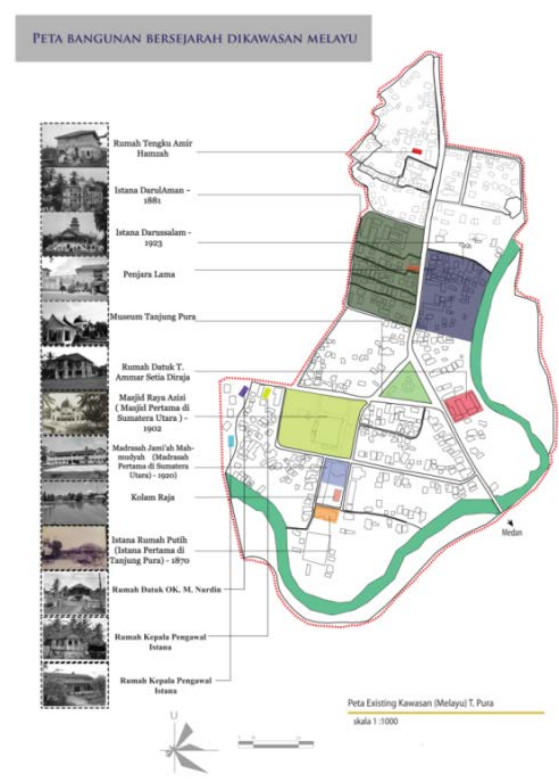

Gambar 3. Kawasan Melayu

Dari hasil survei yang telah dilakukan di Kota Tanjung Pura bahwa Sungai Mati yang saat ini tidak berfungsi akan difungsikan kembali dengan melakukan pengerukan sehingga Sungai Mati ini akan berfungsi kembali sebagai kanal pengendali banjir di Kota Tanjung Pura ini. Selain itu dengan difungsikannya kembali Sungai Mati, secara ekonomis diharapkan akan dapat dimanfaatkan masyarakat sebagai sumber pendapatan baru, dimana masyarakat dapat memanfaatkan aliran sungai ini sebagai objek wisata alternatif seperti memancing atau wisata air lainnya.

Langkah-langkah konservasi yang dapat dilakukan di kawasan Melayu ini yaitu dengan penataan kembali bangunan-bangunan di kawasan ini agar bangunan-bangunan lama yang masuk dalam kategori pelestarian lebih menonjol dari bangunan-bangunan baru. Untuk kawasan permukiman penduduk, perlu adanya penataan kembali agar menghilangkan kesan kumuh, dengan membuat jaringan drainase kota dan memfungsikan kembali kolam Raja yang berada di bagian belakang bangunan masjid sebagai area rekreasi dan sebagai folder yang berfungsi sebagai pengendali banjir di kawasan ini. Dan penataan permukiman ini juga dapat dikembangkan menjadi kawasan sentra industri pengerajin makanan khas Melayu Langkat yang akan berdampak pada pelestarian makanan khas Melayu Langkat.

Penataan permukiman masyarakat Melayu ini dapat dikembangkan sehingga fungsi rumah bukan hanya sebagai tempat tinggal namun dapat juga dimanfaatkan sebagai home stay (penginapan murah), perubahan fungsi ini akan memberikan nilai ekonomis bagi masyarakat dimana wisatawan yang berkunjung ke kawasan ini akan dapat melihat kehidupan masyarakat Melayu Langkat yang masih asli dengan menginap di rumah-rumah penduduk untuk menikmati budaya masyarakatnya. 


\subsubsection{Pemetaan dan Pendataan Bangunan di Kawasan Pecinan}

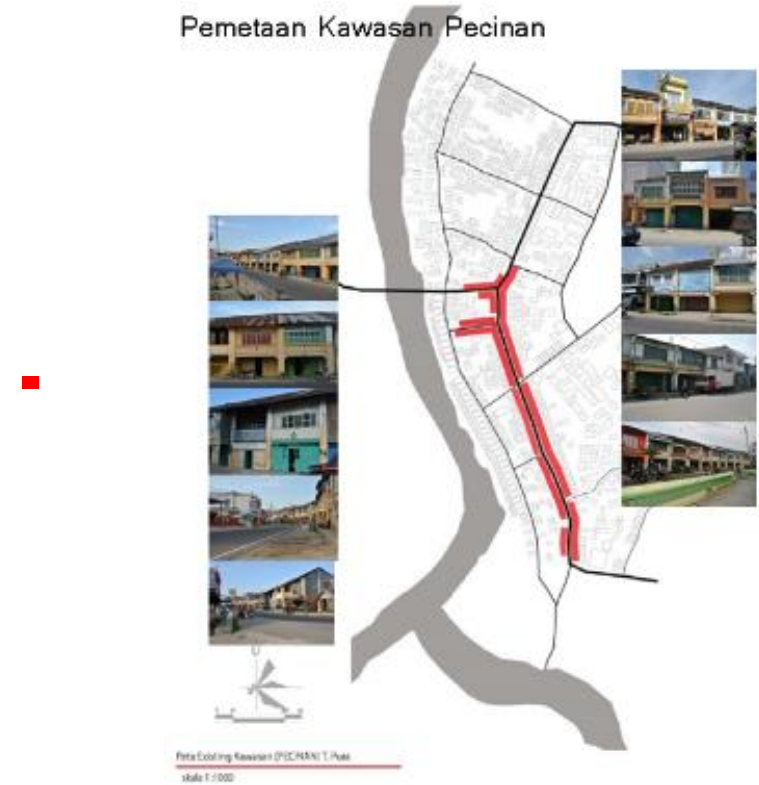

Gambar 4. Kawasan Pecinan

Kondisi eksisting pertokoan lama di kawasan pecinan di Kota Tanjung Pura saat ini telah banyak mengalami perubahan secara visual fasade bangunannya. Perubahan terjadi pada fasade, struktur maupun jumlah lantai.

Dilihat dari kondisi tersebut, pelestarian yang dapat dilakukan ada 2 (dua) alternatif, yaitu:

a. Mengembalikan bentuk fasade bangunan pertokoan yang telah berubah ke bentuk semula

b. Membiarkan bentuk-bentuk yang telah berubah, namun pertokoan-pertokoan yang belum mengalami perubahan harus dipertahankan dan mengusulkan kepada pemerintah daerah agar izin perubahan bangunan pertokoan hanya bisa dilakukan pada bagian belakang bangunan, sehingga fasade depan bangunan pertokoan dapat dipertahankan kelestariannya.

Pelestarian yang dapat dilakukan pada pertokoan lama di Kawasan Pecinan ini adalah penataan lebih terhadap fungsi rumah bukan hanya sebagai tempat tinggal dan pertokoan biasa namun dapat dimanfaatkan sebagai penginapan murah (home stay) sehingga dapat memberikan nilai ekonomi bagi masyarakat dimana wisatawan yang berkunjung ke Kawasan Pecinaan ini akan dapat menikmati budaya kehidupan masyarakat Tionghua dan menjadikan kawasan ini sebagai kawasan wisata kuliner.

Kondisi lain yang harus dilakukan perbaikan adalah tinggi level muka jalan dan sistem drainase. Tinggi muka jalan saat ini telah mengalami perubahan ketinggian yang sangat besar menyebabkan muka lantai bangunan pertokoan semakin rendah dan hal ini menyebabkan bangunan pertokoan sering mengalami banjir. Untuk itu perlu adanya perencanaan drainase yang baik dikawasan ini dan folder yang pada masa lampau dijadikan sebagai penampung air hujan akan dikembalikan fungsinya seperti awal. 


\subsubsection{Pemetaan dan Pendataan Bangunan di Kasawan Belanda}

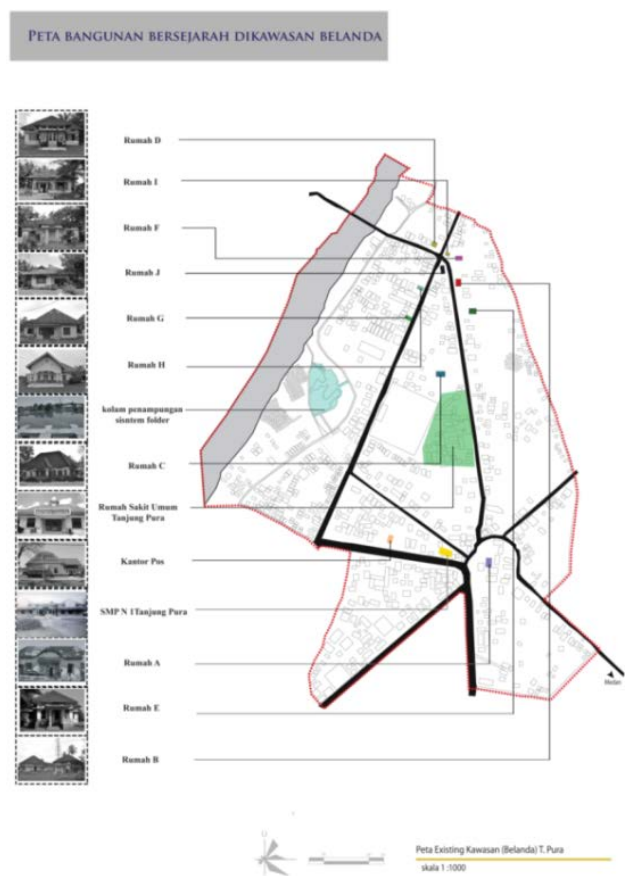

Gambar 5. Kawasan Belanda

Pada kawasan Belanda terdapat beberapa bangunan bergaya kolonial yang sekarang mengalami kerusakan-kerusakan pada fasade, lingkungan dan struktur bangunannya, hal ini disebabkan bangunan tersebut tidak dihuni (kosong) dan tidak jelas siapa pemiliknya.

Berdasarkan kondisi tersebut, dapat dilakukan perawatan dan pengikut sertakan masyarakat dalam tindakan pelestarian yang dilakukan. Tindakan pelestarian yang dapat dilakukan pada bangunan-bangunan tersebut adalah dengan cara rehabilitasi. Lingkungan di kawasan Belanda juga harus dilakukan penataan untuk meningkatkan kualitas lingkungannya dengan cara tindakan konservasi tidak langsung (preservation of deterioration).

Pada kawasan Belanda terdapat kolam penampung folder yang saat ini tidak terawat dan tidak berfungsi disebabkan oleh telah ditempati oleh permukiman masyarakat. Hal tersebut mengakibatkan terjadi banjir di kawasan Belanda dan Kota Tanjung Pura umumnya akibat tidak dapat ditampungnya air dari sungai dan hujan. Melihat kondisi tersebut, kolam penampung folder tersebut harus dikembalikan ke kondisi awalnya sehingga dapat berfungsi seperti semestinya. Selain itu, kolam penampung folder ini harus dilakukan tindakan konservasi untuk menata lingkungannya yaitu dengan jalan konservasi tidak langsung (preservation of deterioration).

\subsection{Rancangan Pelestarian}

Dari hasil survei yang dilakukan data bangunan-bangunan bersejarah di ketiga kawasan tersebut adalah sebagai berikut:

a. Kawasan Melayu terdapat sekitar 10 bangunan bersejarah yang berkaitan dengan Kesultanan Langkat

b. Kawasan Pecinan terdapat sekitar 200 ruko dan 1 kelenteng 
c. Kawasan Belanda terdapat sekitar 16 bangunan yang terdata

Hasil pendataan bangunan-bangunan cagar budaya di 3 kawasan tersebut berupa dokumentasi foto-foto. Sedangkan untuk kawasan yang akan dijadikan objek wisata adalah kawasan lintas Sumatera yaitu dari Jalan Mesjid Raya hingga Jalan Sudirman, dapat dilihat pada gambar 6. Zona berwarna kuning adalah zona rencana pelestarian.
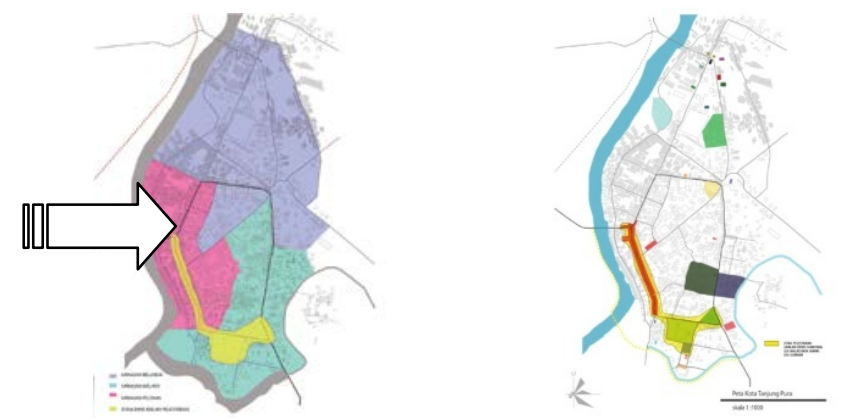

Gambar 6. Kawasan Pelestarian yang Direncanakan

Zona ini diambil karena merupakan pusat Kota Tanjung Pura dan terdapat vocal point yang sangat menarik yaitu keberadaan Masjid Azizi. Pelestarian dilakukan pada kawasan dan bangunan-bangunan yang terdapat di zona ini.

Untuk pelestarian kawasan dilakukan:

a. Kawasan Melayu sebagai pusat aktivitas kegiataan peribadatan islami, pendidikan dan wisata sejarah serta permukiman akan mengalami penataan dengan dilengkapi fasilitas pendukung. Dan Kawasan Pecinaan sebagai pusat aktivitas perdagangan dan perniagaan, wisata sejarah, wisata kuliner, peribadatan khonghucu dan Buddha serta permukiman juga dilakukan penataan.

b. Zona kuning tidak dapat dilalui oleh kendaraan bermotor, untuk jalur kendaraan (jalan lintas Sumatera) dialihkan dengan membuat jalan alternatif.

c. Membuat rancangan drainase kota sehingga agar tidak terjadi banjir, akan dilakukan pembenahan dan perbaikan untuk disesuaikan dengan sistem folder kota yang akan dihidupkan kembali.

d. Merencanakan ruang terbuka untuk umum, taman, kegiatan bazar, jalur hijau, dan lain-lain.

e. Merancang pedestrian yang baik di kawasan sehingga wisatawan akan nyaman menikmati wisata sejarah, arsitektur dan kuliner.

f. Mengembalikan gapura lama sebagai pintu masuk ke kawasan.

g. Merancang fasilitas pendukung seperti sarana parkir kendararaan, tempat peminjaman sepeda, area kuliner dan suvenir.

h. Sungai Sei Batang Serangan dan Sungai Sei Batang Durian yang mengelilingi Kota Tanjung Pura akan dibenahi dan ditata dengan baik dipersiapkan untuk jalur transportasi wisata air.

Untuk pelestarian Bangunan di zona kuning, akan dilakukan:

a. Bentuk bangunan bersejarah akan dikembalikan ke wajah aslinya.

b. Ketinggian pada bangunan baru tidak boleh melebihi bangunan bersejarah yang dilestarikan. 
c. Tidak diperbolehkan untuk melakukan perubahan dan atau penambahan yang menghilangkan bentuk asli dari bangunan bersejarah.

d. Apabila diperlukan penambahan fisik pada bangunan yang dikonservasi tidak boleh terlihat merubah bentuk asli dari bangunan tersebut.

e. Pada bangunan bersejarah yang tinggal puing-puing akan dilakukan pemagaran dan penataan lansekap disekitarnya.

\subsection{Konsep Rancangan Pelestarian}

Kondisi kawasan yang terpilih sebagai Kawasan Pelestarian dan akan difungsikan sebagai kawasan wisata saat ini sangat memprihatikan, seperti pedestrian yang kurang baik dan difungsikan oleh pedagang kaki lima, saluran drainase yang tidak berfungsi dengan baik sehingga masih terjadi banjir, belum adanya sarana pendukung seperti tempat parkir, dan lain-lain.

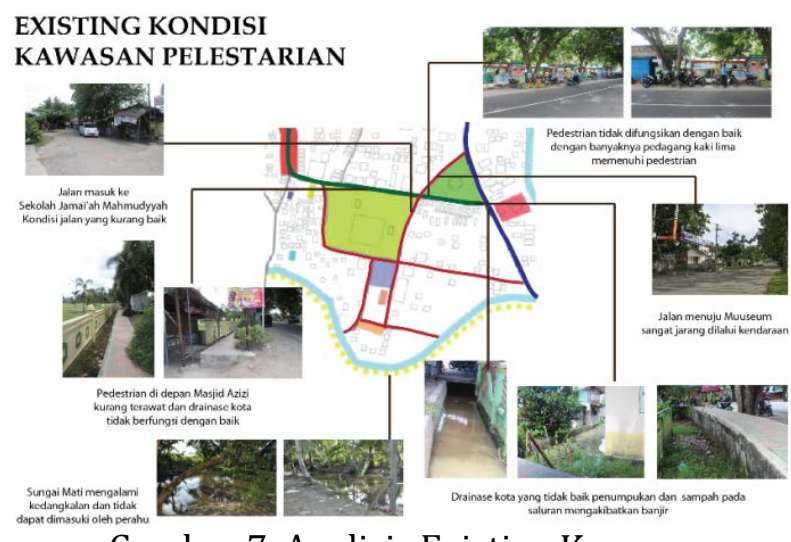

Gambar 7. Analisis Existing Kawasan

Terdapat beberapa potensi di kawasan yang diambil sebagai kawasan pelestarian, selain Masjid Azizi seperti: Museum Tanjung Pura, Kolam Raja, Kelenteng, dan lain-lain.

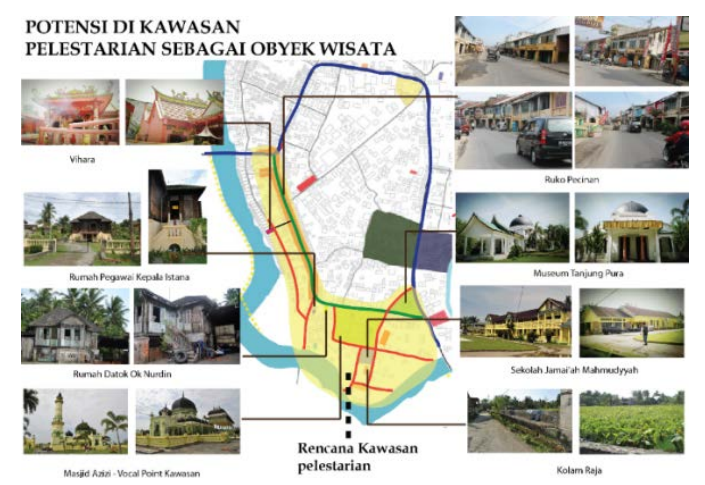

Gambar 8. Analisis Potensi Kawasan Pelestarian

Direncanakaan untuk Kawasan Melayu dan Kawasan Pecinan yaitu dari jalan Masjid hingga jalan Sudirman bebas dari kendaraan bermotor. Jalur ini difungsikan khusus untuk pejalan kaki, bersepeda dan menaiki becak. Jadi untuk jalur sirkulasi lintas Sumatera (dari Medan ke P. Brandan atau sebaliknya) dialihkan mengelilingi kota Tanjung Pura, melewati Kawasan Belanda. 


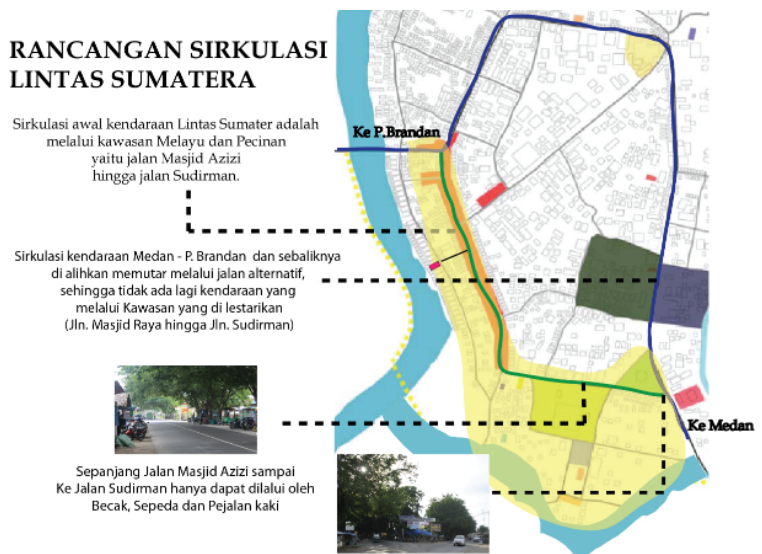

Gambar 9. Rancangan Sikulasi Kendaraan Lintas Sumatera

Untuk konsep kawasan sekitar Jalan Masjid hingga Jalan Sudirman seperti diperlihatkan pada gambar 10, merancang gapura sebaagai pintu masuk ke kawasan, merancang pedestrian dan penataan tepian sungai.

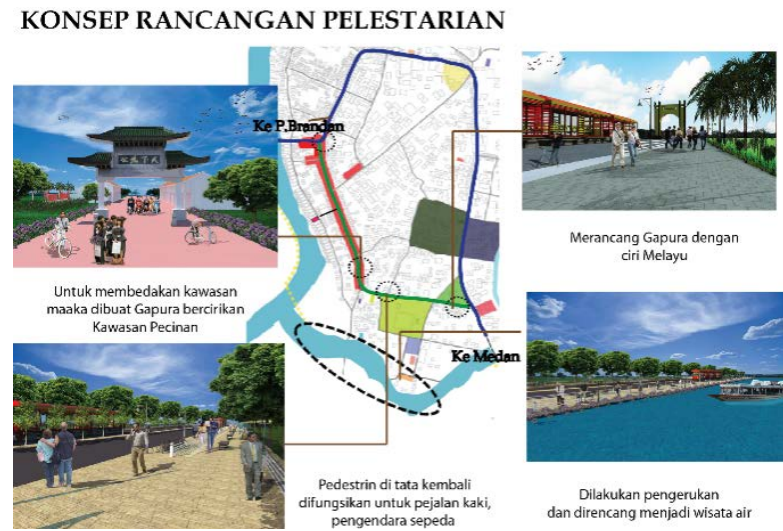

Gambar 10. Konsep Rancangan Kawasan

\section{Kesimpulan}

Kota Tanjung Pura merupakan kota yang memiliki kekayaan budaya dan sejarah yang sangat perlu dilestarikan. Perkembangan Kota Tanjung Pura dapat dilihat dari keberadaan bangunan-bangunan tua yang menyimpan banyak sejarah di masa lampau. Sayangnya saat ini satu persatu situs sejarah tersebut mulai hilang dan rusak. Untuk itu pelestarian Kota Tanjung Pura saat ini sangatlah dianjurkan agar cagar budaya berupa bangunan-bangunan tidak menghilang satu persatu. Dengan mengembalikan wajah kawasan kota akan memunculkan karakter dari Kota Tanjung Pura sehingga memiliki keunikan tersendiri yang menjadi daya tarik wisatawan untuk datang ke Tanjung Pura.

Zona pelestarian yang diambil adalah Jalan Masjid Raya sampai Jalan Sudirman, untuk zona ini dijadikan kawasan bersejarah, kawasan budaya dan menjadikannya sebagai kawasan wisata. Diharapkan dengan pelestarian ini akan meningkatkan taraf perekonomian masyarakat setempat. Untuk perkembangan kota selanjutnya diselaraskan dengan kondisi sejarah Kota Tanjung Pura. 


\section{Daftar Pustaka}

Aldo Rossi. 1991. The Architecture of the City. Cambridge: MIT Press.

Allan, Dobby. 1978. Conservation and Planning. London: Hutchinson.

Arifin, Zainal, 2009. Sekilas Tragedi Bersejarah Brandan Bumi Hangus. Medan: Mitra.

Arifin, Zainal. 2009. Langkat dalam Sejarah dan Perjuangan Kemerdekaan. Medan: Mitra.

Azizu, N.N, Antariksa, Wardhani, D.K. 2011. Pelestarian Kawasan Bentteng Keraton Buton. Jurnal Tata Kota dan Daerah Volume 3, Nomor 1, Juli 2011.

Broadbend. 1994. New Down Town: Ideas City of Tomorow. Singapore: URA \&PMB.

Budiharjo, Eko. 2011. Penataan Ruang dan Pembangunan Perkotaan. Cetakan II. Bandung: PT. Alumni.

Daniel, Perret. 2010. Kolonialisme dan Etnisitas Batak dan Melayu di Sumatra Timur. Jakarta: Kepustakaan Populer Gramedia.

Dirjen Ciptakarya. 1998. Penataan Bangunan dan Lingkungan. Jakarta: Departemen Pekerjaan Umum.

Lynch, Kevin. 1973. The Image of The City. London-England: The MIT Press.

Mansur, Fathurrahman. 2006. Konservasi Dan Revitalisasi Bangunan Lama di Lingkungan Kota Donggala. Majalah Ilmiah "Mektek" Tahun Viii No.2 Mei 2006.

Utomo, Tri Prasetyo. 2005. Tipologi dan Pelestarian Bangunan Bersejarah: Sebuah Pemahaman melalui Proses Komunikasi. Ornamen Jurnal Seni Rupa STSI Surakarta, Vol 2, No. 1 Januari 2005.

Yuliana, K, Kurniati, R. 2013. Upaya Pelestarian Kampung Kauman Semarang sebagai Kawasan Wisata Budaya. Jurnal Teknik PWK Volume 2 Nomor 2, 2013. 